\title{
Tendências em educação qualidade para políticas públicas relacionadas aos livros e à promoção da leitura
}

Trends on quality education for public policies related to books and reading promotion

\section{Everton da Silva Camillo}

Universidade Estadual Paulista (UNESP), Brasil

everton.camillo@unesp.br

(D) https://orcid.org/0000-0003-1314-4372

\section{Fabiana Sala}

Universidade Estadual Paulista (UNESP), Brasil

fabibuel@gmail.com

(DD https://orcid.org/0000-0003-0395-8073

\section{Leda Maria Araújo Lima}

Universidade Estadual Paulista (UNESP), Brasil

le-araujo@hotmail.com

(iD) https://orcid.org/0000-0002-2264-665X

\section{Miriam Fernandes de Jesus}

Universidade Estadual Paulista (UNESP), Brasil

biblioteconomiriam@hotmail.com

(iD https://orcid.org/0000-0003-4125-7649

\section{Sirlaine Galbardo Gomes Costa}

Universidade Estadual Paulista (UNESP), Brasil

sirlaine@unir.br

(iD https://orcid.org/0000-0003-1192-8536

\section{Claudio Marcondes de Castro Filho}

Universidade de São Paulo (USP) / Universidade

Estadual Paulista (UNESP), Brasil

claudiomarcondes@ffclrp.usp.br

(iD https://orcid.org/0000-0003-0889-4291

\section{Resumo:}

A educação de qualidade é o tema do Objetivo de Desenvolvimento Sustentável 4 (ODS 4) da Agenda 2030 das Nações Unidas para o Desenvolvimento Sustentável. O ODS 4 visa garantir uma educação de qualidade inclusiva e equitativa e promover oportunidades de aprendizagem ao longo da vida para todos. Acredita-se que o ODS 4 seja capaz de ajudar a moldar mudanças significativas na sociedade que podem dizer respeito a políticas públicas relacionadas aos livros e à promoção da leitura. Assim, $\mathrm{o}$ estudo objetivou apresentar tendências em educação de qualidade a serem incorporadas nessas políticas públicas. A metodologia baseia-se nas abordagens de pesquisa exploratória e qualitativa-quantitativa. Os dados foram coletados e analisados por meio da aplicação do método de pesquisa análise de conteúdo, que resultou em tendências reais e potenciais para uma educação de qualidade, divididas em tendências temáticas e práticas. $\mathrm{O}$ estudo conclui que as políticas públicas relacionadas aos livros e à promoção da leitura podem ter papéis amplos e complexos na sociedade, ainda mais relacionados à sustentabilidade, igualdade e humanidade. 
Palavras-chave: Políticas públicas, Educação de qualidade, Objetivo de desenvolvimento sustentável, Agenda 2030, Promoção da leitura, Promoção do livro.

\section{ABSTRACT:}

Quality education is the theme of Sustainable Development Goal 4 (SDG 4) of the United Nations 2030 Agenda for Sustainable Development. SDG 4 aims to ensure inclusive and equitable quality education and promote lifelong learning opportunities for all. It is believed that the SDG 4 is able to assist in shaping significant changes in society, which may relate to public policies related to books and reading promotion. Thus, the study aimed at presenting trends on quality education to be incorporated into these public policies. The methodology is based on the exploratory and qualitative-quantitative research approaches. Data was collected and analyzed by applying the content analysis research method, which resulted in real and potential tendencies for quality education both divided into thematic and practical ones. The study concludes that public policies related to books and reading promotion may have broad and complex roles in society further related to sustainability, equality, and humanity.

KEYWORDs: Public policy, Quality education, Reading promotion, Book Promotion, Sustainable development goal, 2030 Agenda.

\section{INTRODUÇÃo}

$\mathrm{Na}$ atualidade, muitos são os desafios enfrentados para se obter acesso aos bens culturais. Quando se leva em consideração o amplo alcance destes, pessoas de vários estratos sociais podem não acessá-los facilmente. Isso se deve, talvez, pela insignificante quantidade de equipamentos culturais que funcionam eficazmente nas cidades, pela falta de aproximação destes da comunidade, pelo investimento financeiro, muitas vezes de alto valor, para acessar o entretenimento cultural ou ainda pelas construções e narrativas sociais que enobrecem ou elitizam as bibliotecas, os museus, os teatros, as galerias de arte, dentre outros espaços e ações culturais, afastando os sujeitos vulneráveis culturalmente da oportunidade de se apropriarem desses espaços e dos seus produtos e serviços. É por essas razões, dentre outras, que políticas públicas viabilizam a democratização da educação e da cultura na sociedade.

Segundo Viana (2014), as políticas públicas vão ao encontro das necessidades e aspirações das pessoas, isto é, aproxima-as de atividades que até então lhes era inacessível. Desse modo, elas são instrumentos políticos planos, decretos, leis etc. - que estabelecem doutrinas e ações que culminam em responsabilidades de governo ou de estado para contornar problemas públicos entendidos como relevantes na sociedade, e, caso sejam formuladas e efetivamente implementadas e asseguradas, representam respostas aos problemas ou anseios de grupos da sociedade.

Para Camillo (2020, p. 67), as políticas públicas são

[...] uma possibilidade de conferir respostas à sociedade, em vista dos problemas que os cidadãos enfrentam em seus macro e micro ambientes para obter acesso pleno aos serviços das cidades, às condições mínimas de sobrevivência, à educação, cultura, saúde e renda compatível com o alto custo de vida na atualidade nas sociedades.

Os sujeitos sociais se deparam com problemas na sociedade que lhes atingem em níveis micro e macro. Interferências desse tipo podem, consequentemente, impedi-los de obter acesso pleno ao bem-estar social e às condições que lhes oportunizam a dignidade como pessoa humana, além de lhes impedir de acessar os serviços nas cidades, a educação, a cultura, a saúde, a renda, a moradia e a oportunidade de trabalho qualificado. Para alcançar essa máxima, a de obter o acesso pleno às condições relevantes para se viver e se desenvolver em sociedade, batalhas político-ideológicas serão travadas no contexto político-econômico-social, pois a adesão de intencionalidade governamental favorável para tanto requer que atores políticos, intersubjetivamente, negociem o que é passível de adentrar a agenda política e o que definitivamente não é (Secchi, 2014).

Hodiernamente, a resolução de problemas deve ser permeada por abordagens inovadoras. Dentre elas, destaca-se o desenvolvimento sustentável. Em 1972, a Conferência de Estocolmo, realizada na Suécia, tratou das questões relacionadas à degradação do meio ambiente. Depois, na década de 1990, houve uma sucessão de 
conferências globais realizadas pela Organização das Nações Unidas (ONU). Ambas tinham como pano de fundo a questão da sustentabilidade. Na verdade, aquelas foram as décadas em que este termo se consolidou, pois foi posicionado na pauta do desenvolvimento socioeconômico de um novo porvir às nações. Assim, em 2015, uma agenda constituída de objetivos e metas alinhados às tendências sustentáveis para as pessoas e o Planeta foi apresentada aos chefes de Estados. Essa agenda é denominada Agenda 2030 (United Nations, 2015a, 2015b).

Essa agenda foi fixada numa conferência de cúpula da ONU em setembro de 2015, em Nova Iorque. Ela é oriunda dos Objetivos de Desenvolvimento do Milênio (ODM). Castro Filho (2018) afirma que os ODM objetivaram melhorar aspectos da vida das pessoas, isto é, suas condições sociais, culturais, econômicas e educacionais no mundo. Contudo, eles foram implicitamente extintos em 2015 quando do anúncio da Agenda 2030 como uma nova proposta de desenvolvimento sustentável às pessoas e ao Planeta. E ainda que os ODM não estejam explicitamente vigentes hoje em dia, eles foram incorporados nos 17 Objetivos de Desenvolvimento Sustentável (ODS) (Figura 1) e, por consequência, nas 169 metas dessa agenda.

FIGURA 1

Os 17 ODS da Agenda 2030

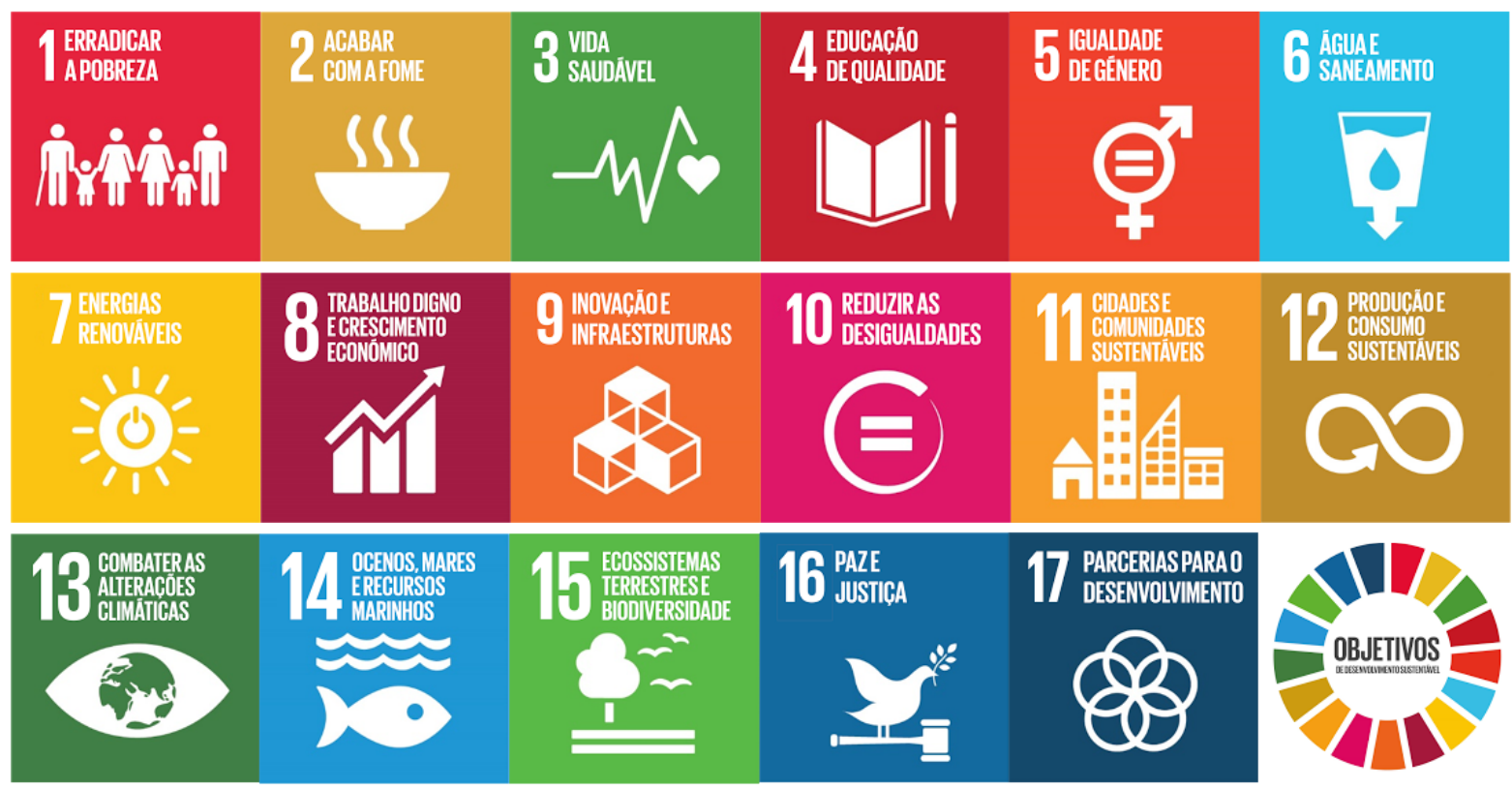

Fonte: https://www.dge.mec.pt/objetivos-de-desenvolvimento-sustentavel-ods/

Os ODS da Agenda 2030 objetivam erradicar a pobreza e a fome no mundo, garantir educação de qualidade e vida saudável às pessoas, bem como assegurar a igualdade de gênero a estas. Eles também visam outras causas humanitárias, como o acesso à água potável e ao saneamento. Chamam atenção para haver mais oportunidades de empregos qualificados às pessoas, o que favorecerá, por consequência, o crescimento econômico das nações, a externalização da inventividade das pessoas e a atuação sustentável das empresas na produção de bens e serviços. Ainda, as cidades no mundo podem adotar fontes renováveis de produção de energia e promover a paz e a justiça social, bem como estabelecer parcerias contundentes para o desenvolvimento social e para combater as mudanças climáticas, que interferem nos ecossistemas terrestre e marinho.

Entretanto, este estudo enfoca unicamente o ODS 4, que objetiva "Assegurar a educação inclusiva e equitativa de qualidade, e promover oportunidades de aprendizagem ao longo da vida para todos." (Plataforma..., 2019, não paginado). Entende-se que quando se promove a educação de qualidade na sociedade as pessoas se apropriam de informação e conhecimento, e, por essa razão, são capazes de tomar 
outros rumos na vida. Sendo assim, elas adentram outras dimensões do desenvolvimento humano, atuam formalmente no mercado de trabalho, participam da fruição entre informação, conhecimento, cultura e educação, aprendem ao longo da vida e rompem com muitas das suas limitações. É nesse sentido que o documento Quality education: why it matters? (United Nations, 2017) apresenta a educação de qualidade e destaca a sua importância para a atual conjuntura de mundo, apoiando as assertivas de Boeren (2019), que entende a educação de qualidade como o principal elemento para atingir os demais ODS da Agenda 2030.

Sendo assim, este estudo parte do pressuposto de que as pessoas atingirão condições sociais, culturais, econômicas e educacionais significativas caso políticas públicas sejam criticamente formuladas, eficientemente implementadas, asseguradas e, quando necessário, oportunamente revisitadas para reformulações. Assim, acredita-se que o ODS 4 tenha condições de auxiliar na conformação de mudanças efetivas na sociedade. Caso ele esteja alinhado às iniciativas de políticas públicas, maiores serão, portanto, as possibilidades de sucesso. E isso pode ser estendido às políticas públicas relacionadas aos livros e à promoção da leitura.

Diante disso, o problema desta pesquisa pode ser traduzido no seguinte: quais são as tendências em educação de qualidade para políticas públicas relacionadas aos livros e à promoção da leitura? Para responder a essa questão, objetivou-se, portanto, apresentar tendências em educação de qualidade para serem incorporadas em políticas públicas relacionadas aos livros e à promoção da leitura.

Esta pesquisa é justificada por desejar obter compreensões acerca de objetivos e metas amplos e complexos que podem ser incorporados em políticas públicas relacionadas aos livros e à promoção da leitura a fim de que se alinhem à busca da educação de qualidade sustentável. Dessa forma, esses documentos podem adquirir funções superiores, de cunhos sustentável, de igualdade e humanitário, um compromisso que vai além das visões "padronizadas" e recorrentes em políticas públicas daquela área acerca do que significa promover a leitura por meio do uso dos livros.

Os dados da pesquisa foram coletados e analisados por meio do método Análise de Conteúdo (AC). O estudo é de nível exploratório, de delineamento documental e de natureza qualitativa-quantitativa.

\section{Metodologia}

Esta é uma pesquisa de nível exploratório, delineamento documental e natureza qualitativa-quantitativa. Sobre a pesquisa documental, Gil (2008) entende que a fonte utilizada nesse tipo de estudo é natureza primária, isto é, ela corresponde aos documentos isentos de tratamento analítico prévio.

Os documentos que constituem a amostra da pesquisa são parte de um universo de investigação entendido como políticas públicas de promoção dos livros, leitura e bibliotecas. Nele, há políticas públicas que correspondem às dimensões doutrinária e prática de políticas públicas. A primeira quer dizer que leis e decretos para promover a leitura determinam a construção de planos de ação para promover esses elementos na sociedade, e contextualizam perspectivas simbólicas e emancipatórias para tanto.

No entanto, esta pesquisa desejou o contrário disso, isto é, obter como amostra do universo os documentos condizentes com a dimensão prática das políticas públicas, que vai em direção à práxis do Governo ou Estado. É nessa dimensão que estão incluídos os documentos chamados de planos de ação. E para esta investigação, destaca-se aqueles que objetivam solucionar problemas sociais e públicos que orbitam a promoção da leitura e uso dos livros - os Planos Nacionais do Livro e Leitura (PNLL). Eles são vistos no Quadro 1, a seguir. 


\section{QUADRO 1 \\ PNLL e suas codificações}

$\begin{array}{llll}\text { País } & \text { Título do documento } & \text { Ano de publicação Código de referência } \\ \text { Argentina } & \text { Plan Lectura - Programa Educativo Nacional para el Mejoramiento de la Lectura } & 2006 & \text { PNLL ARG } \\ \text { Brasil } & \text { Plano Nacional do Livro e Leitura } & 2006 & \text { PNLL BRA } \\ \text { Chile } & \text { Plan Nacional de la Lectura } & 2015 & \text { PNLL CHL } \\ \text { Colômbia } & \text { Plan Nacional de Lectura y Escritura "Leer es mi cuento" } & 2011 & \text { PNLL COL } \\ \text { Equador } & \text { Plan Nacional del Libro y la Lectura 'José de la Cuadra' } & 2017 & \text { PNLL EQD } \\ \text { Paraguai } & \text { Plan Nacional de Lectura "Nandepotyjerahua, em el Paraguay, leemos" } & 2014 & \text { PNLL PAR } \\ \text { Uruguai } & \text { Plan Nacional de Lectura } & 2012 & \text { PNLL URG }\end{array}$

Fonte: elaborado pelos autores

Todos os documentos correspondem a planos de ação de aplicação nacional para promover os livros e a leitura. Eles foram recuperados da base de dados do Centro Regional para el Fomento del Libro em América Latina y el Caribe (CERLALC), especificamente na seção denominada 'Lectura y bibliotecas' e, na sequência, 'Planes y Políticas'. O mês de obtenção dos documentos foi maio de 2020.

Esses são documentos que objetivam promover o livro e a leitura na Argentina, Brasil, Chile, Colômbia, Equador, Paraguai e Uruguai. E há nesse quadro a coluna 'código de referência', criada com a finalidade de servir de remissiva para referenciar o conteúdo de cada PNLL na seção porvir, chamada 'Resultado e discussões'.

A abordagem das pesquisas científicas pode ser de natureza qualitativa ou quantitativa. A escolha da abordagem ideal dependerá de inúmeros fatores da pesquisa, como a hipótese, os pressupostos e o objetivo traçado. As pesquisas qualitativas, alinham-se a objetivos que visam a compreensão de fenômenos e de significados. Essa é uma abordagem que se preocupa cabalmente com os atributos qualitativos da investigação. Por outro lado, as pesquisas quantitativas têm interesse na produção de medidas quantificáveis sobre as características e os comportamentos. Nessa abordagem o pesquisador lança mão de recursos matemáticos e estatísticos para confirmar ou refutar hipóteses (Richardson, 2012). Mediante o objetivo traçado para este estudo, a pesquisa produziu inferências qualitativas e quantitativas e por isso foi considerada de natureza mista - qualitativa-quantitativa.

O pouco conhecimento acumulado de uma área de pesquisa possibilita que novas lacunas sejam identificadas. Dessa forma, quando se tem uma nova lacuna científica é possível haver o surgimento de um novo conhecimento. Por essa razão, as pesquisas exploratórias são comuns a esse objetivo, o de pesquisar em áreas com pouco conhecimento acumulado (Vergara, 2000). Assim, até o presente, são insuficientes os estudos em língua portuguesa sobre políticas públicas relacionadas aos livros e à promoção da leitura na área de Ciência da Informação (CI), e, frente a isso, é fundamental que novas pesquisas alavanquem essa disciplina nessa área, o que justifica a pesquisa ser de nível exploratório.

A coleta e análise dos dados foram feitas por meio da aplicação do método de pesquisa AC. Para Bardin (2016, p. 48), esse método é um:

[...] conjunto de técnicas de análise das comunicações visando obter por procedimentos sistemáticos e objetivos de descrição do conteúdo das mensagens indicadores (quantitativos ou não) que permitam a inferência de conhecimentos relativos às condições de produção/recepção (variáveis inferidas) dessas mensagens.

Em suma, e num sentido amplo, a AC se encarrega de analisar registros de comunicação a partir do emprego de ações sistemáticas para revelar o conteúdo das mensagens. Ela é um método que se estrutura em três 
fases lógicas e ordenadas, e viabilizam a coleta e análise dos dados. Essas fases são: pré-análise; exploração do material; tratamento dos resultados e interpretação.

A fase de 'pré-análise' corresponde a um período de intuições feitas pelo pesquisador. Nela, objetiva-se sistematizar as ideias iniciais de modo que seja estabelecido um percurso lógico para desenvolver as fases sucessivas. É neste momento que os documentos são escolhidos para serem analisados (Bardin, 2016). Os PNLL da amostra constituem o corpus da pesquisa, que é o conjunto de documentos analisados.

$\mathrm{Na}$ sequência, codificar o conteúdo do corpus significa estabelecer a 'exploração do material'. Nessa fase, o processo de categorização auxilia na manipulação dos dados brutos. Bardin (2016) esclarece que ainda que elaborar categorias seja muito comum durante o emprego da $\mathrm{AC}$, isso não se configura como uma obrigatoriedade. Contudo, esta pesquisa objetivou apresentar o conteúdo temático em níveis genérico e restrito do corpus, e, para tanto, importou categorizá-lo.

Isso posto, as categorias da pesquisa foram definidas. $\mathrm{O}$ tipo de procedimento definido para esse processo foi o fechado (Amado, Costa \& Crusoé, 2014). Por procedimento fechado entende-se que as categorias do estudo foram atribuídas a priori. Isso quer dizer que as categorias adotadas são existentes, foram importadas de alguma literatura.

Para esses autores, a adesão de indicadores às categorias é fundamental. Isso possibilita que o processo de classificação, que é próprio da AC, seja feito amparado pelo critério de exclusividade. Ele estabelece que as unidades de registro (UR) - “[...] unidade de significação codificada e corresponde ao segmento de conteúdo considerado unidade de base, visando a categorização e a contagem frequencial” (Bardin, 2016, p. 134) - não devem pertencer a mais de uma categoria concomitantemente. A atribuição de UR às categorias e indicadores deve ser, portanto, exclusiva.

Para esta pesquisa, adotou-se como categorias e indicadores o conteúdo das diretrizes propostas por Camillo (2020) - Diretrizes para formular políticas públicas de promoção do livro, leitura e bibliotecas: foco no ODS 4 da Agenda 2030. Como a somatória de categorias e indicadores formam um sistema categorial, o deste estudo é visto no Quadro 2 a seguir.

\section{QUADRO 2}

Sistema categorial da pesquisa

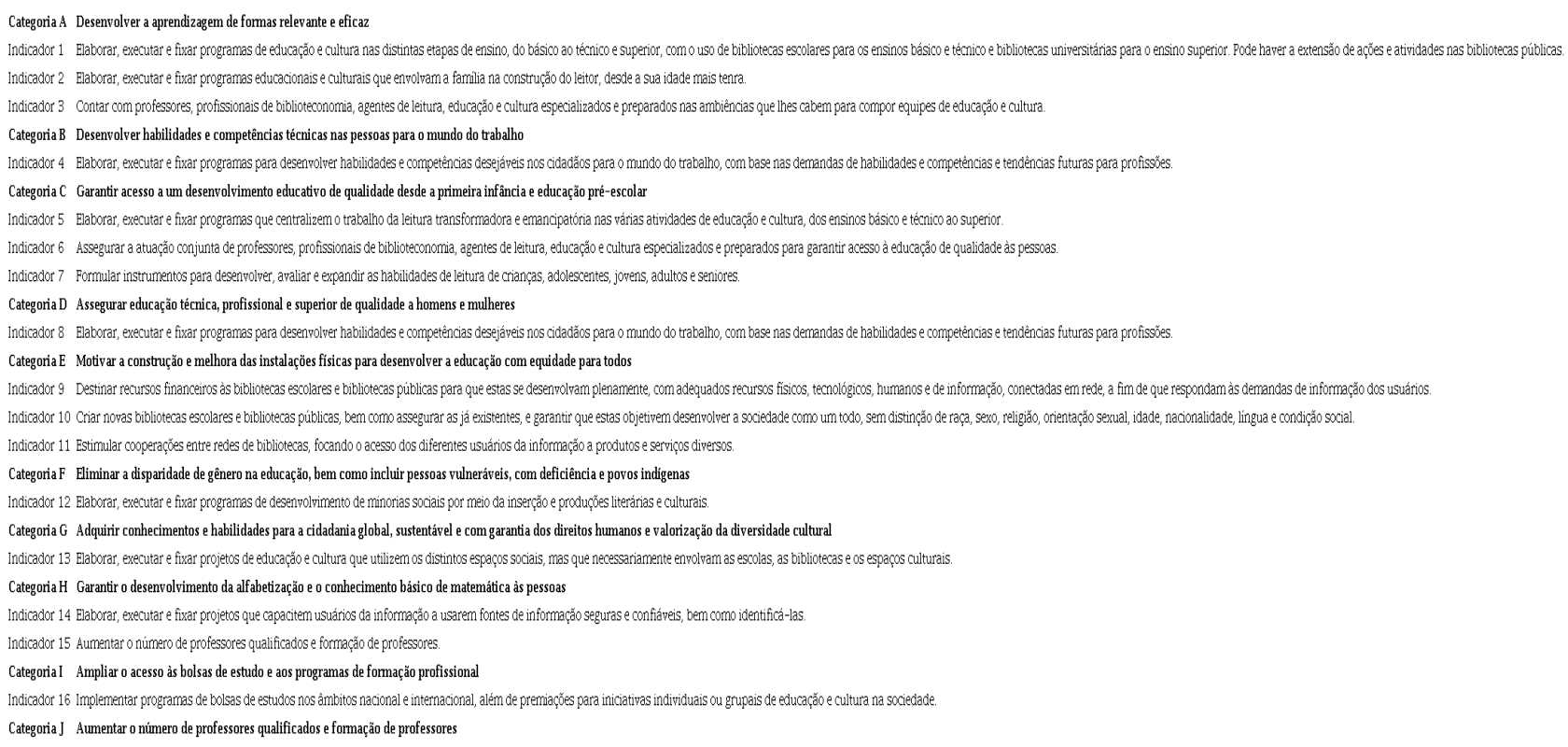


Esse sistema possibilitou congregar as UR do corpus por meio dos indicadores. Assim a última fase da AC é conformada. Chamada de 'tratamento dos resultados e interpretação', nela, as interpretações são feitas pelo analista, o pesquisador. Por meio da sua experiência científica, os dados brutos são explorados e o profissional pode inferir sobre estes. Nesta fase, os esforços cognitivos fazem com que o conteúdo analisado "fale" de si por meio da manipulação do pesquisador, que lhe atribui sentido (Bardin, 2016; Cavalcante, Calixto \& Pinheiro, 2014).

\section{Resultado E Discussões}

Algumas inferências podem ser feitas sobre o conjunto de UR recuperado e sistematizado à luz do sistema categorial da pesquisa. O Gráfico 1 apresenta a distribuição de UR por categoria e indicador, e introduz as discussões.

\section{GRÁFICO 1}

Distribuição de UR por categoria e indicador

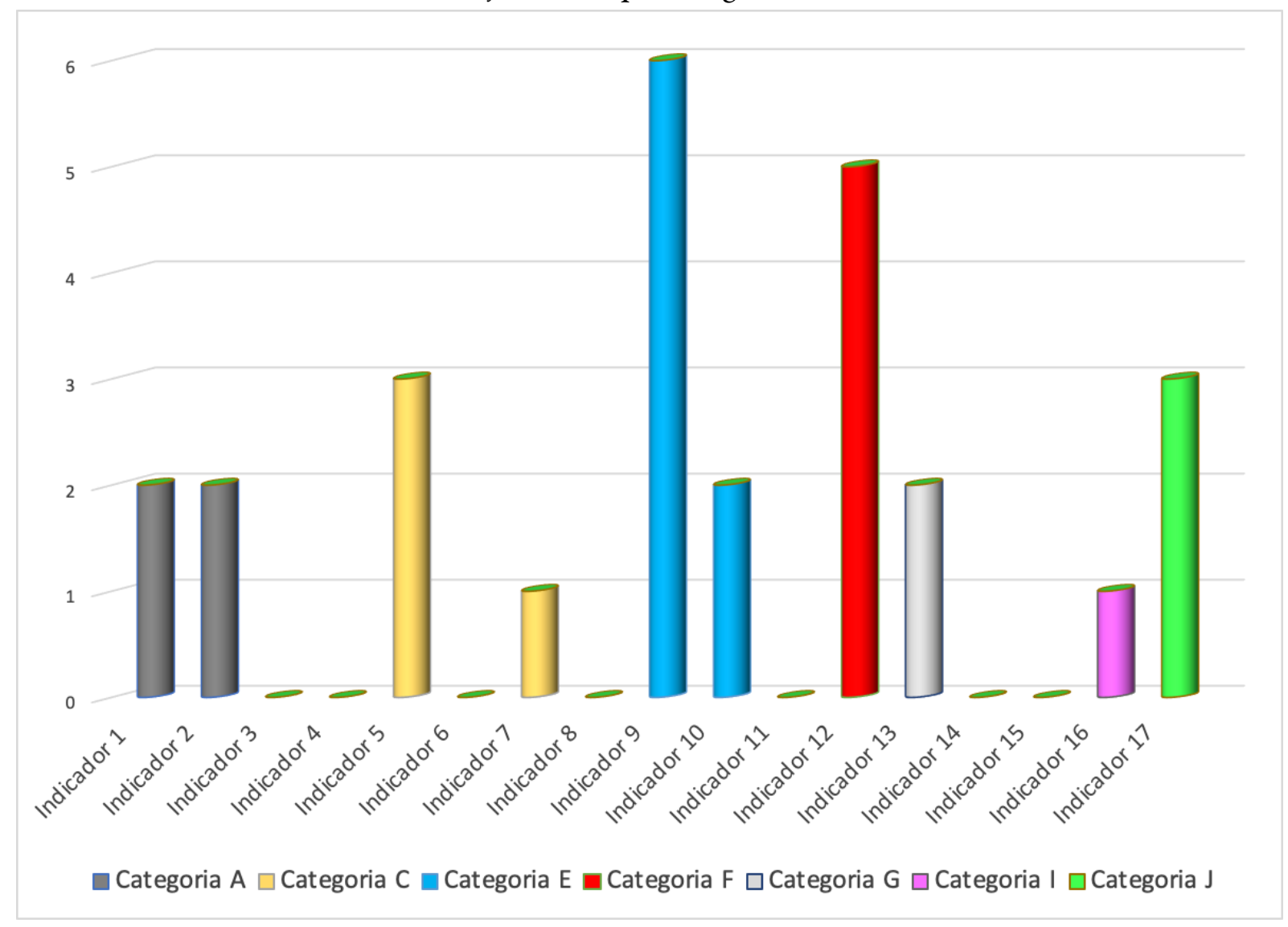

Fonte: dados da pesquisa

Primeiro, é importante destacar que nem todas as categorias do sistema categorial compõem o gráfico acima. Ou seja, entende-se que as categorias que obtiveram UR em seus indicadores foram apenas 7 categorias do total de 10. Portanto, as categorias com UR são as categorias A (Desenvolver a aprendizagem de formas relevante e eficaz), . (Garantir acesso a um desenvolvimento educativo de qualidade desde a primeira infância e educação pré-escolar). . (Motivar a construção e melhora das instalaçôes físicas para desenvolver a educação com equidade para todos). . (Eliminar a disparidade de gênero na educação, bem como incluir pessoas vulneráveis, 
com deficiência e povos indígenas), . (Adquirir conhecimentos e habilidades para a cidadania global, sustentável e com garantia dos direitos humanos e valorização da diversidade cultural). . (Ampliar o acesso às bolsas de estudo e aos programas de formação profissional) e. (Aumentar o número de professores qualificados e formação de professores).

Dessas categorias, nota-se que a ., sobre 'Motivar a construção e melhora das instalações físicas para desenvolver a educação com equidade para todos', é a que detém o maior número de UR, 8 no total. E as UR dessa categoria estão vinculadas a apenas dois dos seus três indicadores, que são o 9 e 10.

O indicador 9 demonstra a ação ligada ao objetivo 'Destinar recursos financeiros às bibliotecas escolares e bibliotecas públicas para que estas se desenvolvam plenamente, com adequados recursos físicos, tecnológicos, humanos e de informação, conectadas em rede, a fim de que respondam às demandas de informação dos usuários'. Esse indicador possui 6 UR. Elas são:

Fortalecer el lugar y papel superlativo que deben ocupar las bibliotecas en el ámbito escolar, apoyando y aumentando las existentes y propendiendo a crear aquellas que no existan (PNLL ARG).

Assegurar a implantação, modernização e qualificação de espaços, instalações e equipamentos, bem como a formação e desenvolvimento de acervos, de modo a garantir serviços de qualidade em bibliotecas escolares e nas de acesso público nos municípios brasileiros (PNLL BRA).

Incentivar e fomentar a constituição de acervos que garantam a produção local, territorial e nacional, que preservem a memória e contribuam para o entendimento da diversidade cultural brasileira (PNLL BRA)

Fomentar las ediciones electrónicas y facilitar el acceso a contenidos digitales em bibliotecas públicas (PNLL CHL).

Fortalecer las bibliotecas y espacios de lectura como el instrumento por excelencia de la democratización en el acceso al libro (PNLL CHL).

Fortalecer las condiciones de las bibliotecas públicas del país, a través del mejoramiento de la infraestructura bibliotecaria (PNLL COL).

O indicador 10, sobre 'Criar novas bibliotecas escolares e bibliotecas públicas, bem como assegurar as já existentes, e garantir que estas objetivem desenvolver a sociedade como um todo, sem distinção de raça, sexo, religião, orientação sexual, idade, nacionalidade, lingua e condição social', se relaciona com 2 UR. Elas são:

Incentivar e fomentar a criação, manutenção, modernização e expansão permanente de bibliotecas e espaços de leitura e de convivência e promoção literária, considerando a acessibilidade e a diversidade física, geográfica, arquitetônica e cultural brasileira (PNLL BRA).

Diseñar y poner en funcionamiento bibliotecas que sean verdaderos espacios de encuentro de la comunidad (PNLL EQD).

Sobre as relações estabelecidas no âmbito da categoria E, é possível depreender algumas tendências. Compreende-se que os PNLL ARG, BRA, CHL, COL e EQD, em âmbito temático, visam, sobretudo, motivar a construção e melhora das instalações físicas para desenvolver a educação com equidade para todos. Depois, e mais especificamente, esses documentos anseiam que recursos financeiros sejam destinados às bibliotecas escolares e bibliotecas públicas para que ambas se desenvolvam plenamente, com adequados recursos físicos, tecnológicos, humanos e de informação, e que sejam/estejam conectadas em rede. Outro objetivo específico tem relação com criar novos desses tipos de biblioteca, bem como assegurar as já existentes e garantir que objetivem desenvolver a sociedade como um todo, sem distinção de raça, sexo, religião, orientação sexual, idade, nacionalidade, língua e condição social.

Os PNLL ARG, BRA, CHL, COL e EQD têm, portanto, foco nas bibliotecas escolares e públicas. Em ambas, o cerne está na asseguração de acervo diverso e nas manifestações física e digital da literatura. É importante que essas bibliotecas preservem a memória social local, territorial e nacional. Também se objetiva 
o fortalecimento da infraestrutura desses espaços, bem como sua modernização. Isso favoreceria, até mesmo, a promoção da leitura em suportes eletrônicos, seguindo a crescente tendência mundial em leitura textual.

$\mathrm{Na}$ sequência, a categoria $\mathrm{F}$ é a segunda mais significativa dentre as demonstradas no Gráfico 1 . Ela detém 5 UR. Seu espectro temático diz respeito a 'Eliminar a disparidade de gênero na educação, bem como incluir pessoas vulneráveis, com deficiência e povos indigenas'. As UR dessa categoria se vinculam ao indicador 12, sobre 'Elaborar, executar e fixar programas de desenvolvimento de minorias sociais por meio da inserção e produções literárias e culturais’. As UR são:

Assegurar o acesso à leitura e à informação a todas as pessoas com deficiência, conforme a legislação brasileira (PNLL BRA).

Assegurar o acesso à leitura e à informação a todos os brasileiros, com especial atenção às minorias, grupos étnicos, tradicionais, entre outros, conforme a legislação brasileira (PNLL BRA).

Garantizar que la lectura y el acceso al libro sean utilizados como fuente de información y aprendizaje, y para la integración de los pueblos indígenas y de las personas con capacidades diferentes (PNLL CHL).

Impulsar el rescate de la identidad de los pueblos originários (PNLL CHL).

Fomentar la creación y el emprendimiento editorial de los pueblos indígenas (PNLL CHL).

No que se refere a eliminar a disparidade de gênero na educação, assim como incluir pessoas vulneráveis, com deficiência e povos indígenas, os PNLL BRA e CHL são destacados. Esses documentos focam as pessoas com deficiência, os grupos étnicos e tradicionais e os povos indígenas e originários. A todos eles, desejase ofertar o acesso pleno à informação e à leitura, garantindo, assim, o acesso ao livro e a outras fontes de informação e aprendizagem, além de se vislumbrar a criação de um conselho editorial para as publicações de autoria indígena. São ambições que se aliançam, portanto, à meta específica de elaborar, executar e fixar programas de desenvolvimento de minorias sociais por meio da inserção e produções literárias e culturais.

As categorias A e C são a terceira mais significativa dentre as apresentadas no Gráfico 1 . Ambas têm 4 UR cada. A seguir, destaca-se, primeiro, a categoria A. A categoria $C$ será apresentada mais adiante.

A categoria A diz respeito, ao menos em âmbito temático, a 'Desenvolver a aprendizagem de formas relevante e eficaz'. As UR dessa categoria estão divididas igualmente entre os indicadores $\mathbf{1}$, que trata de 'Elaborar, executar e fixar programas de educação e cultura nas distintas etapas de ensino, do básico ao técnico e superior, com o uso de bibliotecas escolares para os ensinos básico e técnico e bibliotecas universitárias para o ensino superior. Pode haver a extensão de ações e atividades nas bibliotecas públicas', e ., relacionado a 'Elaborar, executar e fixar programas educacionais e culturais que envolvam a familia na construção do leitor, desde a sua idade mais tenra'. O indicador 3, que objetiva 'Contar com professores, profissionais de biblioteconomia, agentes de leitura, educação e cultura especializados e preparados nas ambiências que lhes cabem para compor equipes de educação e cultura', não obteve UR.

As UR presentes na categoria A são:

Propender al desarrollo de competencias lectoras a través de acciones educativas en todos los niveles del sistema, facilitando procesos de apropriación de los bienes culturales y generando una didáctica en la formación de lectores que permita reinstalar una positiva práctica de la lectura en el espacio curricular en la escuela (PNLL ARG).

Propiciar la construcción de un país de lectoras y lectores, que tengan en la lectura una base sólida de sustentación del crecimiento, y a la información como una herramienta para la inclusión social; la democratización, como aporte esencial al desarrollo humano y el fortalecimiento de su identidad (PNLL ARG).

Promover acciones por la lectura en familia y en otros espacios de convivencia (PNLL ARG). 
Promover el gusto por la lectura desde edades tempranas, en los niños, adolescentes y jóvenes, propiciándola como práctica permanente, teniendo en cuenta la habitualización necesaria del sujeto como lector y facilitando su acercamiento a los textos y libros (PNLL ARG).

As UR demonstram que apenas o PNLL ARG tem metas relacionadas com o desenvolvimento da aprendizagem de formas relevante e eficaz. Ele pretende desenvolver as competências de leitura nas pessoas por meio de ações educativas e em todos os níveis do sistema de ensino, do básico ao superior. Isso possibilita a apropriação dos bens culturais pelas pessoas no âmbito do ensino formal nas escolas, colégios e universidades. Assim, atividades estabelecidas à leitura podem compor o currículo escolar.

Ainda, a leitura tem que oferecer a base sólida para que as pessoas se desenvolvam de forma sólida e sejam incluídas socialmente por meio dela. E é nesse sentido que a leitura deve ser compreendida como ferramenta possibilitadora e fomentadora do desenvolvimento humano e do fortalecimento da identidade 'sujeitiva'.

De outro lado, a categoria C, que intenciona 'Garantir acesso a um desenvolvimento educativo de qualidade desde a primeira infância e educação pré-escolar', possui UR que se ligam aos indicadores 5 (Elaborar, executar e fixar programas que centralizem o trabalho da leitura transformadora e emancipatória nas várias atividades de educação e cultura, dos ensinos básico e técnico ao superior) e. (Formular instrumentos para desenvolver, avaliar e expandir as habilidades de leitura de crianças, adolescentes, jovens, adultos e seniores).

As UR parte da categoria $C$ são:

Elevar los niveles de lectura (comportamiento lector y comprensión lectora) en todo el país haciendo de la lectura no sólo un factor de esparcimiento y crecimiento personal, sino un instrumento intelectual que permita a las personas acceder a mejores condiciones de vida, generando nuevas capacidades para participar activa y democraticamente en la sociedad (PNLL ARG).

Contribuir para a formação de leitores autônomos, buscando, de maneira continuada, substantivo aumento do índice nacional de leitura e do nível qualitativo das leituras realizadas, considerando os diferentes públicos (PNLL BRA).

Transformar las prácticas lectoras tradicionales - de todos los actores educativos - con el fin de formar lectores autónomos, críticos y capaces de mejorar su calidad de vida (PNLL PAR).

Mejorar el nivel de comprensión lectora de niños, niñas, adolescentes, jóvenes y adultos en relación a los parámetros de las evaluaciones internacionales (PNLL PAR).

O conteúdo da categoria C é protagonizado pelos PNLL ARG, BRA e PAR. As UR dessa categoria consistem em elevar a qualidade e nível da leitura, contribuir para a formação de leitores autônomos, transformar as práticas de leitura tradicionais e desenvolver a compreensão em leitura de crianças, jovens, adultos e seniores.

Em vista desses objetivos, entende-se que a leitura deve ser compreendida no âmbito de sociedade dos referidos PNLL como um instrumento intelectual que confere condições para as pessoas atingirem melhores condições de vida. E isso pode ser concretizado quando do desenvolvimento qualitativo da leitura. Logo, o foco da leitura deve estar no desempenho, compreensão, atribuição de sentido aos códigos textuais, vinculando-os à vida dos sujeitos. Assim, aumenta-se a probabilidade de se formar leitores autônomos, críticos e capazes de melhorar sua qualidade de vida quando os sujeitos se tornam leitores efetivos.

A categoria J, que tematicamente visa 'Aumentar o número de professores qualificados e formação de professores', é a quarta com o maior número de UR. São 3 UR. Elas se vinculam ao seu único indicador - o indicador 17. Este se refere a 'Implementar programas de mobilidade internacional para fomentar a formação e a capacitação de profissionais da educação e da cultura para trabalharem em ações significativas de promoção do livro, leitura e bibliotecas na sociedade'. Suas UR são: 
Fomentar a formação continuada e o intercâmbio de gestores públicos, professores, bibliotecários, mediadores e agentes de leitura, contribuindo para o compartilhamento de experiências, uso e aplicação de tecnologias sociais para a promoção da leitura e o acesso à informação (PNLL BRA).

Desarrollar programas de formación a bibliotecarios, docentes, mediadores de lectura y escritura, estudiantes y otros gestores culturales, por medio de talleres, seminarios y videconferencias (PNLL EQD).

Formar a los responsables de espacios de lectura en bases conceptuales y estrategias para desarrollar actividades de animación a la lectura (PNLL URG).

A categoria J conta com a presença dos PNLL BRA, EQD e URG. Ela tem UR que objetivam a participação profissional. Nota-se o anseio pelo intercâmbio de gestores públicos culturais e educacionais com profissionais ligados à educação e cultura, como professores, bibliotecários, mediadores e agentes de leitura. Estima-se que o trabalho conjunto, e com formação continuada desses profissionais, pode oportunizar o compartilhamento de experiências e uso e aplicação de tecnologias sociais para promover a leitura e o acesso à informação. Assim, a formação de leitores pode acontecer com base em planos adequadamente estabelecidos de modo multidisciplinar, tendo como cenário a adesão das confluências entre gestores e profissionais da linha de frente.

A categoria G dispõe de 2 UR. Seu tema está relacionado com o intento de 'Adquirir conhecimentos e habilidades para a cidadania global, sustentável e com garantia dos direitos humanos e valorização da diversidade cultural. Ela possui apenas um indicador - indicador 13. $\mathrm{O}$ objetivo de que esse indicador se vale é 'Elaborar, executar e fixar projetos de educação e cultura que utilizem os distintos espaços sociais, mas que necessariamente envolvam as escolas, as bibliotecas e os espaços culturais’. As UR são vistas a seguir:

Aumentar la oferta pública y el acceso a libros en espacios no convencionales con especial atención en la población infantil (PNLL COL).

Fortalecer el papel de la lectura en el sistema educativo y en espacios alternativos (PNLL PAR).

As duas UR da categoria $\mathrm{G}$ emitem uma mensagem. Faz-se entender que os usuários da informação devem ter contato com a literatura e com os livros em espaços não convencionais de acesso a esses elementos. Portanto, alternativas não convencionais para promover a leitura na sociedade são uma importante pauta em discussões que envolvem os gestores públicos e profissionais envolvidos com a educação e a cultura. É nesse sentido que o papel das bibliotecas e da leitura pode ser (re)significado à população e permear os sistemas de ensino existentes.

Por fim, a última categoria com UR é apresentada. Ela, que é a categoria I, conta com 1 UR. Tematicamente, ela pretende 'Ampliar o acesso às bolsas de estudo e aos programas de formação profissional. O indicador 16 é seu único, e consiste em 'Implementar programas de bolsas de estudos nos âmbitos nacional e internacional, além de premiações para iniciativas individuais ou grupais de educação e cultura na sociedade'.

A UR relacionada a esse indicador é a seguinte:

Incentivar e fomentar programas de bolsas de criação, formação, intercâmbio, pesquisa e residências literárias nacionais e internacionais (PNLL BRA).

A compreensão de que haver bolsas de formação, intercâmbio, pesquisa e residência literária nacional e internacional na área do livro, leitura e bibliotecas pode incentivar a qualificação de profissionais ligados às áreas da educação e cultura do país. A vivência com experiências educacional-culturais estrangeiras incrementa a visão dos profissionais sobre diferentes modos de produzir educação e gerar cultura. Isso resultaria numa perspectiva de promoção da leitura munida de experiências internacionais inovadoras nessa área por enriquecer as competências técnicas dos profissionais. Quiçá não seja esse um dos critérios-chave capazes de viabilizar o início de revoluções educacionais e culturais na sociedade, mesmo que ele tenha sido 
pouco vislumbrado nos PNLL analisados. Assim, essa meta foi vista apenas no PNLL BRA, o que representa uma intenção registrada apenas no documento brasileiro.

A seguir, a Figura 2 representa a organização decrescente das categorias mais significativas do estudo por meio de uma pirâmide invertida.

FIGURA 2

Categorias mais significativas do estudo em ordem decrescente

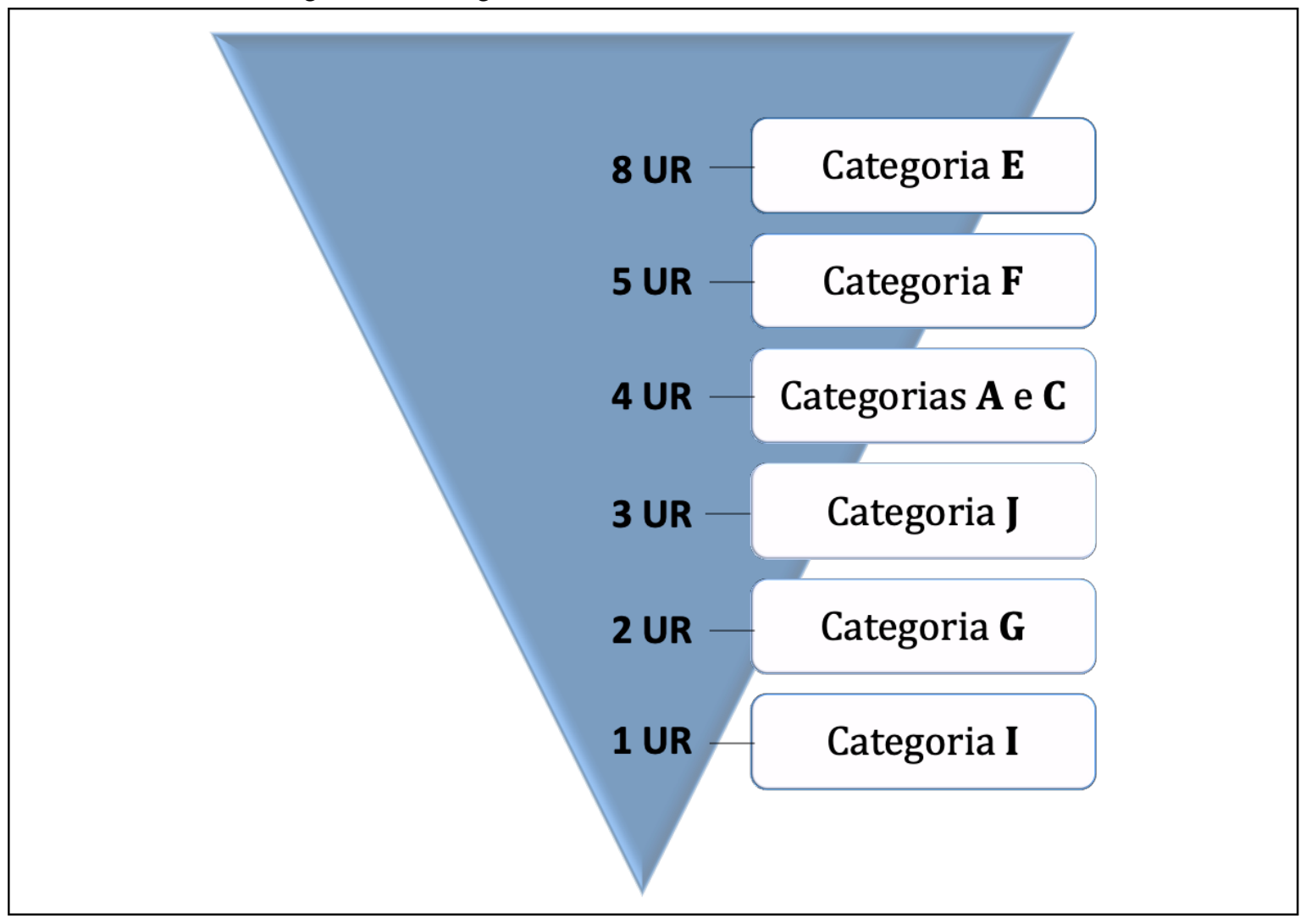

Fonte: dados da pesquisa

É fundamental esclarecer que essa ordem foi estabelecida com base no número de UR por categoria, partindo da que tem o maior valor - categoria $\mathrm{E}$ - à que tem o menor - categoria I.

Os PNLL analisados apresentam algumas tendências. Para apresentá-las, calculou-se o valor médio das categorias. Desse modo, procedeu-se à aferição ao aplicar a fórmula

$$
x=\frac{x+x+x+[?][?[?]+x}{n}
$$

em que os numeradores constituem o número de UR por categoria e o denominador, o número de categorias com UR. O valor médio obtido foi 3,86 , resultado da equação

$$
x=\frac{8+5+4+4+3+2+1}{7}
$$

Contudo, as UR fundam-se na pesquisa como números inteiros e não como números fracionados, por isso o valor médio com o qual as inferências são feitas é o valor 4, determinado por aproximação. Isso quer dizer que 3,86 é aproximadamente igual a $4(3,86 \cong 4)$. A relação dos dados com o valor médio pode ser vista no Quadro 3, a seguir. 
QUADRO 3

Relação de categorias com valores acima e abaixo da média

\begin{tabular}{|c|c|c|}
\hline Categorias & no de UR & \% em relação ao total \\
\hline Categoria E & 8 & 29 \\
\hline Categoria F & 5 & 22 \\
\hline Categoria A & 4 & 14 \\
\hline Categoria C & 4 & 14 \\
\hline \multicolumn{3}{|c|}{ Valor médio: 4} \\
\hline Categoria J & 3 & 11 \\
\hline Categoria G & 2 & 7 \\
\hline Categoria I & 1 & 3 \\
\hline Total & 27 & 100 \\
\hline
\end{tabular}

Fonte: dados da pesquisa

As categorias E, F, A e C estão acima do valor médio, que foi estabelecido como sendo aproximadamente 4, e por isso foram consideradas tendências reais. E abaixo do valor médio estão as categorias J, G e I, por esse motivo consideradas tendências potenciais.

As tendências reais ligadas à educação de qualidade nos PNLL relacionam-se propriamente aos temas: (1) motivar a construção e melhora das instalações físicas para desenvolver a educação com equidade para todos; (2) eliminar a disparidade de gênero na educação, bem como incluir pessoas vulneráveis, com deficiência e povos indígenas; (3) desenvolver a aprendizagem de formas relevante e eficaz; e (4) garantir acesso a um desenvolvimento educativo de qualidade desde a primeira infância e educação pré-escolar.

Além disso, as tendências potenciais dizem respeito aos seguintes temas: (1) aumentar o número de professores qualificados e formação de professores; (2) adquirir conhecimentos e habilidades para a cidadania global, sustentável e com garantia dos direitos humanos e valorização da diversidade cultural; e (3) ampliar o acesso às bolsas de estudo e aos programas de formação profissional.

O conteúdo da tendência real dos PNLL revela alguns caminhos. Primeiro, entende-se que esses documentos são políticas públicas relacionadas aos livros e à promoção da leitura, e, por sê-las, compreendem que a promoção desses elementos deve ocorrer em instalações físicas que instiguem o desejo pela leitura e a congregação de interessados por esta, quer sejam crianças, jovens, adultos ou seniores. A educação de qualidade se alinha a essa intenção. Depois, quando se olha as bibliotecas públicas, em especial, compreendese que estas são, por natureza, espaços que congregam públicos de credo, origem, língua, idade, condição física, social e financeira, orientação sexual, gênero, raça, nível de formação escolar e ideologia de vida e política distintos. $\mathrm{E}$ as bibliotecas constituem lugares para que o binômio ensino-aprendizagem ocorra de modos eficaz, efetivo e pertinente.

No que se refere ao conteúdo da tendência potencial, os PNLL demonstram preocupação com aumentar o número de professores qualificados e a formação dos mesmos, além de visar a formação de outros profissionais. Isso significa que algumas políticas públicas relacionadas aos livros e à promoção da leitura 
preocupam-se com a qualidade da atuação profissional de professores e outras categorias profissionais. Em virtude mesmo de se obter educação de qualidade, essas são ações fundamentais capazes de potencializar as expectativas do ODS 4 nas sociedades. Contudo, nem todos os documentos adotam a mesma visão. Apenas alguns o fazem. Só quando da adesão de visões conjuntas será possível perspectivar com maior contundência e equilíbrio o desenvolvimento da cidadania global, sustentável, com garantia dos direitos humanos e valorização da diversidade cultural nas bibliotecas, escolas e espaços não-convencionais de promoção da educação e cultura.

No âmbito das tendências reais para se obtiver educação de qualidade por meio de políticas públicas relacionadas aos livros e à promoção da leitura, algumas ações se destacam, a saber: (1) destinar recursos financeiros às bibliotecas escolares e bibliotecas públicas para que estas se desenvolvam plenamente, com adequados recursos físicos, tecnológicos, humanos e de informação, conectadas em rede, a fim de que respondam às demandas de informação dos usuários; (2) criar novas bibliotecas escolares e bibliotecas públicas, bem como assegurar as já existentes, e garantir que estas objetivem desenvolver a sociedade como um todo, sem distinção de raça, sexo, religião, orientação sexual, idade, nacionalidade, língua e condição social; (3) elaborar, executar e fixar programas de desenvolvimento de minorias sociais por meio da inserção e produções literárias e culturais; (4) elaborar, executar e fixar programas de educação e cultura nas distintas etapas de ensino, do básico ao técnico e superior, com o uso de bibliotecas escolares para os ensinos básico e técnico e bibliotecas universitárias para o ensino superior; (5) elaborar, executar e fixar programas educacionais e culturais que envolvam a família na construção do leitor, desde a sua idade mais tenra; (6) elaborar, executar e fixar programas que centralizem o trabalho da leitura transformadora e emancipatória nas várias atividades de educação e cultura, dos ensinos básico e técnico ao superior; e (7) formular instrumentos para desenvolver, avaliar e expandir as habilidades de leitura de crianças, adolescentes, jovens, adultos e seniores.

A seguir, as tendências potenciais para se obter educação de qualidade por meio de políticas públicas relacionadas aos livros e à promoção da leitura se relacionam, especificamente, às seguintes ações: (1) implementar programas de mobilidade internacional para fomentar a formação e a capacitação de profissionais da educação e da cultura para trabalharem em ações significativas de promoção do livro, leitura e bibliotecas na sociedade; (2) elaborar, executar e fixar projetos de educação e cultura que utilizem os distintos espaços sociais, mas que necessariamente envolvam as escolas, as bibliotecas e os espaços culturais; e (3) implementar programas de bolsas de estudos nos âmbitos nacional e internacional, além de premiações para iniciativas individuais ou grupais de educação e cultura na sociedade. A seguinte Figura 3 consolida hierarquicamente as todas as tendências. 


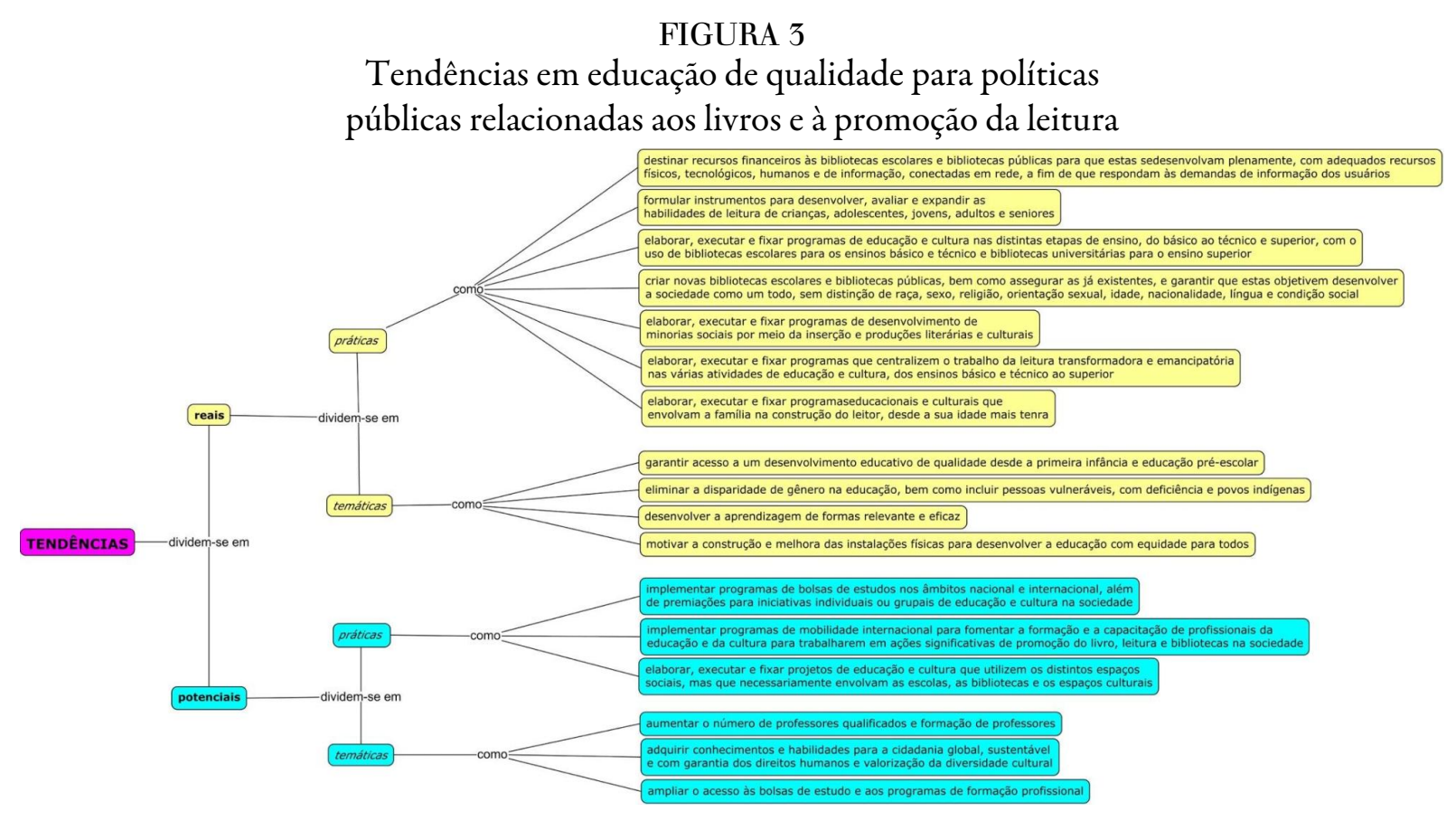

Fonte: dados da pesquisa

O conteúdo da Figura 3 demonstra as tendências reais e potências em educação de qualidade para políticas públicas relacionadas aos livros e à promoção da leitura. Isso indica que quando da reformulação desses instrumentos políticos nas esperas municipal, estadual e federal, essas tendências podem ser incorporadas como objetivos e metas relacionados à educação de qualidade para promover a leitura de modo amplo e complexo.

As tendências classificadas como 'reais' são as que satisfatoriamente existem na relação entre as políticas públicas relacionadas aos livros e à promoção da leitura analisadas e o ODS 4 da Agenda 2030, como averiguado. Mas as tendências classificadas como 'potenciais' são as que incipientemente existem naquela relação, e por isso podem se tornar tão reais quanto àquelas. Entretanto, para que isso seja conformado é necessário também incluir as tendências potenciais sob a forma de objetivos e metas em políticas públicas municipais, estaduais e federais do livro, leitura e bibliotecas.

Finalmente, as tendências temáticas consistem na apresentação dos temas em que ações específicas devem ser elaboradas. Para cada tema é possível haver ações que se preocupem em garantir aspectos de educação de qualidade sob diferentes aspectos. E essas ações específicas são, portanto, as tendências práticas.

\section{CONSIDERAÇÕES FINAIS}

A educação de qualidade é o tema do ODS 4 da Agenda 2030. Ele visa a promoção da educação sob uma filosofia inclusiva e equitativa, orientada a conferir oportunidades de aprendizagem ao longo da vida às pessoas de todas as idades. Por essa razão, acredita-se que políticas públicas relacionadas aos livros e à promoção da leitura podem ganhar em função social caso incorporem objetivos e metas ligados à visão sustentável para a educação inerente ao ODS 4. Desse modo, o objetivo da pesquisa, que consistiu em apresentar tendências de educação de qualidade para serem incorporadas em políticas públicas relacionadas aos livros e à promoção da leitura, foi atingido.

O processo investigativo resulta na apresentação de dois tipos de tendências: reais e potenciais. As primeiras são as que satisfatoriamente existem na relação entre as políticas públicas relacionadas aos livros e à promoção da leitura analisadas e o ODS 4 da Agenda 2030. A segunda, no entanto, são as que incipientemente foram 
detectadas naquela relação. Mas podem se concretizar como reais caso sejam implementadas, assim como as outras, em políticas públicas municipais, estaduais e federais do livro, leitura e bibliotecas. Além disso, há subdivisões das tendências reais e potenciais. Elas são as tendências temáticas e práticas. As primeiras se referem à apresentação dos temas em que ações específicas devem ser elaboradas, ao passo que as segundas são essas ações em si.

Compreendem-se, assim, as políticas públicas relacionadas aos livros e à promoção da leitura podem ter objetivos e metas amplos e complexos para sociedade. Eles podem estar alinhados à educação de qualidade sustentável ao mesmo tempo em que preconizam a promoção da leitura. Por esse motivo, políticas públicas daquela área que incorporarem objetivos e metas segundo o ODS 4 da Agenda 2030 poderão obter papéis sociais melhor alinhados à sustentabilidade, igualdade e humanidade.

\section{REFERÊNCIAS}

Amado, J.; Costa, P. e Crusoé, N. (2014). A técnica de Análise de Conteúdo. En J. Amado (Coord.), Manual de investigação qualitativa em educação (pp. 301-351). Coimbra: Imprensa da Universidade de Coimbra.

Bardin, L. (2016). Análise de conteúdo. São Paulo: Edições 70.

Boeren, E. (2019). Understanding Sustainable Development Goal (SDG) 4 "quality education" from micro, meso and macro perspectives. International review of education, 65, 277-294 Recuperado de https://link.springer.com/ar ticle/10.1007/s11159-019-09772-7

Camillo, E. S. (2020). Diretrizes para formular politicas públicas de promoção do livro, leitura e bibliotecas: foco no ODS 4 da Agenda 2030 (Tésis de maestría). Universidade Estadual Paulista "Júlio de Mesquita Filho", Faculdade de Filosofia e Letras, Marília. Recuperado de http://hdl.handle.net/11449/191535

Castro Filho, C. M. (2018). Agenda 2030 para o desenvolvimento sustentável: uma leitura de política pública na clave da biblioteca escolar. Revista digital de biblioteconomia e ciência da informação, 16(3), 355-372. Recuperado de h ttps://periodicos.sbu.unicamp.br/ojs/index.php/rdbci/article/view/8650931

Cavalcante, R. B.; Calixto, P. e Pinheiro, M. M. K. (2014). Análise de conteúdo: considerações gerais, relações com a pergunta de pesquisa, possibilidades e limitações do método. Informação \& sociedade: estudos, 24(1), 13-18. Recuperado de http://www.periodicos.ufpb.br/ojs/index.php/ies/article/view/10000

Gil, A. (2008). Métodos e técnicas de pesquisa social. São Paulo: Atlas.

Plataforma Agenda 2030. (2019). Objetivo 4: educação de qualidade. Recuperado de http://www.agenda2030.com.b r/ods/4/

Richardson, R. J. (2012). Pesquisa social: métodos e técnicas. São Paulo: Atlas.

Secchi, L. (2014). Políticas públicas: conceitos, esquema de análise, casos práticos. São Paulo: Cengage Learning.

United Nations. (2015a). Momento de ação global para as pessoas e o planeta. Recuperado de https://nacoesunidas.o $\mathrm{rg} / \mathrm{pos} 2015 /$ ods4/

United Nations. (2015b). Transforming our world: the 2030 Agenda for the Sustainable Development. Recuperado de https://www.un.org/ga/search/view_doc.asp?symbol=A/RES/70/1\&Lang=E

United Nations. (2017). Quality education: why it matters? Recuperado de: https://www.un.org/sustainabledevelop ment/wp-content/uploads/2018/09/Goal-4.pdf

Vergara, S. C. (2000). Projetos e relatórios de pesquisa em administração. São Paulo: Editora Atlas.

Viana, L. (2014). Bibliotecas escolares: politicas públicaspara a criação depossibilidades. (Tésis de maestría). Universidade de São Paulo, Escola de Artes e Comunicação, São Paulo. Recuperado de https://www.teses.usp.br/teses/dispo niveis/27/27151/tde-18122014-094444/publico/VIANALilian_corrigida.pdf 